\title{
Current Status of Ketamine and Related Therapies for Mood and Anxiety Disorders
}

\author{
Sara Costi $^{1}$ • Nicholas T. Van Dam ${ }^{1}$ - James W. Murrough ${ }^{1,2,3}$
}

Published online: 1 October 2015

(C) Springer International Publishing AG 2015

\begin{abstract}
Major depressive disorder (MDD) is a leading cause of disability worldwide. Despite a plethora of established treatments, less than one third of individuals with MDD achieve stable remission of symptoms. Given limited efficacy and significant lag time to onset of therapeutic action among conventional antidepressants, interest has shifted to treatments that act outside of the monoamine neurotransmitter systems (e.g., serotonin, norepinephrine, and dopamine). Preclinical and clinical research on the glutamate system has been particularly promising in this regard. Accumulating evidence shows support for a rapid antidepressant effect of ketamine - a glutamate $N$-methyl-D-aspartate (NMDA) receptor antagonist. The present article reviews the pharmacology, safety, and efficacy of ketamine as a novel therapeutic agent for mood and anxiety disorders. The majority of clinical trials using ketamine have been conducted in patients with treatment-resistant forms of MDD; recent work has begun to examine ketamine in bipolar disorder, post-traumatic stress disorder, and obsessive-compulsive disorder. The impact of ketamine on suicidal ideation is also discussed. The current status and prospects for the identification of human biomarkers of ketamine treatment
\end{abstract}

This article is part of the Topical Collection on Mood and Anxiety Disorders

James W. Murrough

james.murrough@mssm.edu

1 Mood and Anxiety Disorders Program, Department of Psychiatry, Icahn School of Medicine at Mount Sinai, One Gustave L. Levy Place, Box 1230, New York, New York 10029, USA

2 Fishberg Department of Neuroscience, Icahn School of Medicine at Mount Sinai, New York, NY, USA

3 Friedman Brain Institute, Icahn School of Medicine at Mount Sinai, New York, NY, USA response and hurdles to treatment development are considered. We conclude by considering modulators of the glutamate system other than ketamine currently in development as potential novel treatment strategies for mood and anxiety disorders.

Keywords Depression · Antidepressant · Anxiety · Mood disorder $\cdot$ Ketamine $\cdot$ Glutamate

\section{Introduction}

Depression is the leading cause of disability-adjusted life years across age groups, with approximately 300 million cases worldwide in 2010 [1]. A recent assessment revealed that mood disorders had the highest total costs per person (approximately $€ 115,000$ or US $\$ 125,000$ ) of all major brain disorders [2]. Thus, depression represents a major challenge to the medical and scientific communities. The STAR*D trial, the largest "real-world" study of depressed patients, reports that only approximately one third of patients remitted after initial treatment with citalopram, a selective serotonin reuptake inhibitor (SSRI). Following three additional sequential treatment steps, one third of patients failed to achieve remission [3, 4]. Commonly, patients who do not response to at least two different antidepressant therapies are considered to have treatmentresistant depression (TRD). As a group, those with TRD suffer from a prolonged course of illness, significant functional impairment, and are at heightened risk for suicide [5]. Despite a wealth of neuroscience research and increasing knowledge concerning the putative pathophysiology of depression, no medications with fundamentally novel mechanisms of action have come to market since the introduction of monoamine modulators in the mid-twentieth century. 
The observed rapid-onset antidepressant effect of the glutamate $N$-methyl-D-aspartate (NMDA) receptor (NMDAR) antagonist ketamine has engendered hopefulness among both clinicians and researchers [6]. Ketamine is a widely used anesthetic agent, which exerts a high-affinity noncompetitive blockade of the NMDAR. In the 15 years since ketamine was first tested as a treatment for depression [6], a wave of new scientific investigation has examined the role of the NMDAR and the glutamate system in the neurobiology of mood and anxiety disorders and the potential of these systems as targets for novel therapeutics. The current article begins with a brief review of the glutamate system and NMDAR as it relates to depression and subsequently provides a critical review of the state of the field concerning ketamine as a candidate therapeutic agent in TRD. Recent researches examining the therapeutic potential of ketamine for the treatment of suicidal ideation, bipolar disorder, post-traumatic stress disorder (PTSD), and obsessive-compulsive disorder (OCD) are reviewed. The hypothesized mechanisms of action of ketamine are considered, and glutamatergic agents other than ketamine currently under investigation as novel therapeutic candidates are discussed.

\section{Role of the Glutamate System and NMDA Receptor in Depression}

The monoaminergic hypothesis of depression states that depression is caused, at least in part, by alteration within the serotonin, norepinephrine, or dopamine systems. As the shortcomings of the monoaminergic hypothesis have become apparent, interest in other neurotransmitter systems has grown. The glutamate system, in particular, has emerged as an important focus of research in mood disorders. Glutamate is the principle excitatory neurotransmitter in the central nervous system (CNS). In patients with mood disorders, studies have reported abnormal levels of glutamate in circulating blood [7, 8], cerebrospinal fluid [9], and brain tissue, both from magnetic resonance spectroscopy (1H-MRS) studies [10] and from post-mortem analyses [11-13]. Although observed differences in glutamate can be difficult to interpret (for example, due to the potential confounding effects of drug exposure or effects related to the post-mortem state), a relationship between alterations in the glutamate system and depression is increasingly appreciated [5, 14, 15].

Glutamate exerts its action through the binding of cell surface receptors, conventionally divided into two families based on their structure and function: ionotropic or metabotropic. The former (ionotropic) includes NMDA, $\alpha$-amino-3-hydroxy-5-methyl-4-isoxazolepropionic acid (AMPA), and kainate receptors (KA), while the latter (metabotropic) are designated mGluR1-mGluR7 based on their chemical structure and functionally grouped as types I, II, or III, based on their effects on signal transduction pathways [16, 17]. Three families of NMDA receptor subunits have been identified: NR1 (crucial for neurodevelopment and present throughout the brain), NR2 (developmentally regulated and expressed in neocortex, forebrain, cerebellum, diencephalon, and brain stem), and NR3 (developmentally regulated and expressed in the neocortex, cerebellum, and hippocampus) [17]. There are four different NR2 subunits (NR2A-D), and among these, the NR2B subunit (expressed primarily in the forebrain) may be particularly relevant in depression: levels of NR2B are significantly reduced in the prefrontal cortex of major depressive disorder (MDD) patients [18], and treatment development efforts have focused on the NR2-B subunit of the NMDAR, in particular [19, 20]. Recently, specific polymorphisms related to the gene coding for the NR2B subunit (GRIN2B) were associated with risk for TRD [21]. A post-mortem study reported higher expression of GRIN2B in patients with MDD who died by suicide compared to MDD patients who did not die by suicide [22]. Taken together, accumulating data support an important role for the NMDAR and the glutamate system in mood disorders.

\section{Pharmacology of Ketamine}

\section{Pharmacokinetics and Route of Administration}

The pharmacokinetics and bioavailability of ketamine are strongly influenced by the route of administration. Bioavailability is approximately $99 \%$ when given intravenously (IV), $93 \%$ when given intramuscularly, 25-50\% when given intranasally (IN), and 16-20\% when administered orally, though peak effects occur rapidly regardless of administration method [23, 24].

Ketamine reaches its maximum plasma concentrations in less than $1 \mathrm{~min}$ with (IV) 5-15 min with intramuscular and 30-60 min with oral administration. It is associated with a high systemic clearance (about $1 \mathrm{~L} / \mathrm{min}$ ) and short plasma half-life (approximately $1-3 \mathrm{~h}$ ) [25]. The primary active metabolite of ketamine is norketamine, resulting from $N$-demethylation of ketamine by the enzymes CYP3A4, CYP2B6, and CYP2C9. The relative plasma concentration of ketamine and norketamine can differ significantly as a result of oral $(1: 15)$ versus intravenous administration (1:1) [26].

The relationship between ketamine, its metabolites, and antidepressant effects is complex. Despite a half-life of approximately $2 \mathrm{~h}$ [27], a single infusion of ketamine is commonly associated with antidepressant effects lasting upward of 1 week or longer [28]. Continued antidepressant effects after the clearance of ketamine suggest that the observed clinical effects may be partially due to downstream molecular and cellular consequences of NMDAR blockade (see "Pharmacodynamics and Mechanism of Action" section). 
Prolonged effects of ketamine may also involve its metabolites. One recent study suggests that the metabolic decomposition of ketamine may vary between unipolar and bipolar depression and further that high plasmatic concentrations of the metabolite hydroxynorketamine were related to a lack of antidepressant response in bipolar patients [29].

\section{Pharmacodynamics and Mechanism of Action}

At anesthetic dose, the blockade of NMDARs by ketamine leads to a decrease of excitatory transmission in the prefrontal cortex [30]. At subanesthetic dose, however, the drug causes an increase in extracellular concentration of glutamate [30]. It is hypothesized that the increase in glutamate release following low-dose ketamine administration results from preferential antagonism of NMDAR on inhibitory GABA interneurons, thereby releasing inhibition on glutamatergic pyramidal neurons [31]. This chain of events leads to activation of other glutamatergic receptors, including AMPA receptors, as demonstrated in the prefrontal cortex using rodent models [30]. The activation of AMPA receptors is associated with increased synaptic protein expression; neural growth and differentiation; synaptogenesis; and increase in the number, morphology, and activity of synapses [32-34]. The effects of ketamine on NMDAR are dependent on the basal state of the receptor at the time of drug administration. For active NMDARs, ketamine leads to augmented glutamate release and increased excitatory activity. For inactive NMDARs, ketamine leads to the inhibition of eukaryotic elongation factor (eEF2) kinase, with subsequent up-regulation of brain-derived neurotrophic factor (BDNF), downstream effects of which include enhancement of synaptic plasticity $[35,36]$.

Data from animal models suggests that the antidepressant effects of ketamine are a consequence of downstream effects of mediators of synaptic plasticity, likely triggered as a consequence of a burst in glutamate signaling described above. Low-dose ketamine appears to increase the expression of numerous post-synaptic proteins (Arc, PSD-95, GluR1, and synapsin I); increase phosphorylation of mTOR, p70S6k, and 4E-BP1 (all proteins involved in synaptogenesis); and increase synaptic spine number and maturity [37]. These findings suggest that rapid up-regulation of synaptogenesis is likely an important component of ketamine's rapid antidepressant effect.

Recent evidence indicates that glycogen synthase kinase-3 (GSK-3) may be involved in ketamine's antidepressant effect [38]. Knockout mice lacking GSK-3 did not exhibit the expected antidepressant response to ketamine. GSK3 is critically involved in synaptic deconsolidation (also known as synaptic pruning) - the opposite of synaptogenesis. These findings are consistent with knowledge of a role for GSK-3 in mood disorders [39] and the hypothesized role of GSK-3 in the mechanism of action for lithium
[40]. Moreover, these findings suggest the possibility of reinforcing the antidepressant action of ketamine, or preventing relapse, through concurrent administration of a GSK-3 inhibitor (e.g., lithium).

In addition to the direct effects of ketamine on glutamate and its effects of molecular regulators of neuroplasticity, studies suggest that ketamine may be antidepressant via regulations of inflammatory mediators, including IL- $1 \beta$, IL-6, IL10 , and tumor necrosis factor alpha (TNF- $\alpha)[41,42]$. Inflammatory cytokines have been shown to interact with glutamate pathways in several important ways, including effects on the expression of glutamate transporters and on the activity of the glutamine synthetase (responsible for the conversion of glutamate to glutamine) $[43,44]$. Ketamine has been shown to reduce IL- 6 , IL- 8 , and TNF- $\alpha$ production in human cells [45], and in a sample of 16 patients with TRD, ketamine responders exhibited a reduction of peripheral cytokines (i.e., IL-1 $\beta$ and IL-6) at $230 \mathrm{~min}$ and up to 3 days postadministration [46]. Consistent with the inflammatory hypothesis of depression [47], these findings, although preliminary, could offer new explanations for the rapid antidepressant effect elicited by ketamine, especially when considering that depressed patients exhibit elevated levels of the proinflammatory cytokine IL-6 in circulating serum or plasma compared to controls [48].

\section{Ketamine Administration in Mood and Anxiety Disorders}

\section{Ketamine Administration in Unipolar Depression}

There is a growing literature describing the antidepressant effect of ketamine and its potential therapeutic actions on MDD or TRD. In this section, we first summarize the main findings from randomized controlled trials (RCT) of ketamine in unipolar depression (see Table 1) and subsequently summarize the data for uncontrolled studies. Sections that follow consider the evidence for therapeutic effects of ketamine in bipolar depression, PTSD, OCD, and ketamine for the treatment of suicidal ideation (SI).

The first randomized trial to assess the effects of a single infusion of a subanesthetic dose of ketamine $(0.5 \mathrm{mg} / \mathrm{kg})$ in patients with MDD was published 15 years ago [6]. The study consisted of a placebo-controlled crossover trial conducted on a small sample $(n=7)$ and reported a marked decrease in depressive symptoms, as measured by the 25 -item Hamilton Depression Rating Scale (HAM-D), after 240 min from the administration of the drug (decrease in HAM-D scores of 14 \pm 6 SD 10 points vs. $0 \pm 12$ points during ketamine and placebo, respectively). The antidepressant response lasted $72 \mathrm{~h}$ following the infusion with a return to baseline symptomatology in 1 to 2 weeks after infusion. Findings from subsequent RCTs of a 
Table 1 Randomized controlled trials of ketamine in mood disorders, OCD, and PTSD

\begin{tabular}{|c|c|c|c|c|c|c|c|c|}
\hline Study & Route & Dose $(\mathrm{mg} / \mathrm{kg})$ & Treatment schedule & Diagnosis & $N$ & Design & $1^{\circ}$ outcome & Response rate $^{\mathrm{a}}(\%)$ \\
\hline Berman et al. [6] & IV & 0.5 & Single & MDD & 7 & Crossover & HAM-D & 50 \\
\hline Zarate et al. [49] & IV & 0.5 & Single & MDD (TR) & 17 & Crossover & HAM-D & 71 \\
\hline Lapidus et al. [50] & $\mathrm{IN}$ & 0.5 & Single & MDD (TR) & 18 & Crossover & MADRS & 44 \\
\hline Murrough et al. $[51,52]$ & IV & 0.5 & Single & MDD (TR) & 72 & Parallel-arm & MADRS & 64 \\
\hline Valentine et al. [53] & IV & 0.5 & Single & MDD & 10 & Crossover & HAM-D & - \\
\hline Diazgranados et al. [54] & IV & 0.5 & Single & BPD (TR) & 18 & Crossover & MADRS & 56 \\
\hline Zarate et al. [55] & IV & 0.5 & Single & BPD (TR) & 15 & Crossover & MADRS & 79 \\
\hline Rodriguez et al. [56] & IV & 0.5 & Single & OCD & 15 & Crossover & Y-BOCS & $50^{\mathrm{b}}$ \\
\hline Feder et al. [57] & IV & 0.5 & Single & PTSD & 35 & Crossover & IES-R & - \\
\hline
\end{tabular}

$I V$ intravenous, $I M$ intramuscular, $I N$ intranasal, $M D D$ major depressive disorder, $T R$ treatment resistant, $B P D$ bipolar disorder, $O C D$ obsessivecompulsive disorder, PTSD post-traumatic stress disorder, HAM-D Hamilton Depression Rating Scale, MADRS Montgomery-Asberg Depression Rating Scale, RCT randomized controlled trial, Y-BOCS Yale-Brown Obsessive-Compulsive Scale, IES-R Impact of Event Scale-Revised

${ }^{a}$ Response rate was defined as reduction $\geq 50 \%$ in primary outcome measure, unless otherwise noted

${ }^{\mathrm{b}}$ Response rate was defined as reduction $\geq 35 \%$ of primary outcome measure

single infusion of ketamine in MDD utilizing a crossover design showed similar results $[49,51,53]$. Zarate et al. [49] reported a significant improvement in depressive symptoms following ketamine infusion compared to placebo at $24 \mathrm{~h}$ and at 1 week in a sample of 17 TRD subjects. In a smaller sample $(n=10)$, a single-blind trial by Valentine et al. [53] reported a rapid $(1 \mathrm{~h})$ and sustained (at least 7 days) antidepressant effect of ketamine. The same rapid improvement in depression severity $24 \mathrm{~h}$ after ketamine was reported also by Murrough et al. [51] in a two-site trial conducted on a sample of 73 TRD subjects. In this work, in order to preserve the validity of the blind, the authors used the active placebo midazolam, a benzodiazepine able to replicate the sedative and effects of IV ketamine. While the general adverse events were similar across the two groups, transient dissociative side effects experienced by the ketamine-treated subjects were higher.

Overall, a single infusion of ketamine in MDD appears to be well tolerated in the abovementioned RCTs with response rates (defined as a reduction of $\geq 50 \%$ from baseline through clinician-assessed depression severity) that varied between $50 \%$ [6] and $71 \%$ [49]. Recently, an RCT [50] investigated the antidepressant effect of ketamine while given through a different route of administration: a sample of 18 MDD was treated with a single IN administration of ketamine. This double-blind, crossover study reported a response rate of $44 \%$ that persisted for 2 days after the administration.

In addition to these controlled trials, several uncontrolled clinical studies have been published describing the antidepressant effect of ketamine in cohorts of MDD and TRD patients. These showed response rates that varied from $30 \%$ [58] to $80 \%$ [59]. Overall, ketamine appears well tolerated, with mild psychotomimetic and dissociative symptoms, usually resolving within a few hours following administration.

Given the short-lived effects of a single infusion (approximately 7 days to full symptomatic relapse), several researchers, through open-label designed trials, have focused on strategies in order to prolong the antidepressant effect of ketamine. Some of those studied the association with another agent (riluzole), while others examined the effect of repeated infusion of ketamine. Riluzole, a FDA-approved drug for the treatment of amyotrophic lateral sclerosis, has been studied in association with ketamine but failed in demonstrating a difference in time to relapse when compared to placebo after an initial infusion with ketamine in 42 subjects with MDD [60] and 14 with TRD [61], respectively. Several researchers, through open-label designed trials, have examined the effect of repeated infusion of ketamine in an effort to obtain a prolonged antidepressant effect [52, 59, 62-65]. Aan het Rot et al. [62] reported six IV infusions of ketamine administered three times per week over $40 \mathrm{~min}$ at a $0.5 \mathrm{mg} / \mathrm{kg}$ dose in a sample of ten TRD patients, some of whom had formerly displayed a positive response to a single IV ketamine infusion. Psychotomimetic, dissociative symptoms, and vital sign fluctuations were transient and returned to baseline following each infusion. The response duration of repeated ketamine infusions was greater than the duration for a single infusion ( $50 \%$ of patients retained remission for more than 2 weeks following the final ketamine infusion). The aforementioned sample was subsequently amplified $(n=24)$ [52]: the rapid antidepressant effect in TRD was predictive of a sustained antidepressant effect with a median time to relapse of 18 days (the subjects were monitored until 83 days after the last infusion), with a rapid response to ketamine infusion as a prognostic indicator for maintained antidepressant effect over the 
course of treatment. Shiroma et al. [65] replicated the findings in a sample of 14 patients on a stable dose of antidepressant medications, suggesting that safety and efficacy of repeated ketamine infusions may generalize beyond medication-free patients. The authors reported response and remission rates of 92 and $67 \%$, respectively, after six-repeated ketamine infusions in a sample of 14 TRD subjects, who were on a stable dose of antidepressant medications for at least 2 months prior to study onset. Co-administration of ketamine and other antidepressants appeared safe, and these preliminary findings might suggest a synergistic effect between traditional antidepressants and ketamine. Clearly, larger studies with better control are needed to further explore these possibilities.

Several studies have evaluated the combination of electroconvulsive therapy (ECT) and ketamine in patients with mood disorders, using the drug as the anesthetic agent [66-68] or at subanesthetic doses $[69,70]$. The use of subanesthetic doses of ketamine, in addition to the standard anesthetic used before ECT, failed to demonstrate a sustained improvement in depressive symptoms compared to thiopental + ECT [70] and placebo + ECT [69]. Contrariwise, trials studying the effect of ketamine as the anesthetic agent in ECT report significant improvement in depressive symptoms compared to the usual anesthesia $[67,68]$. A retrospective study reports an improvement in HAM-D scores and a reduced number of ECT sessions needed for a ketamine group compared to a barbiturate thiopental group [66].

\section{Ketamine Administration in Bipolar Depression}

To our knowledge, there have only been two RCTs examining the antidepressant effects of ketamine in individuals with bipolar depression $[54,55]$. Both studies showed rapid antidepressant effects at $40 \mathrm{~min}$ post-infusion with a response duration of 4.5-6.8 days (on average). It should be noted that all patients in these studies were maintained on a mood stabilizer (lithium or valproate). Neither study reported an increased risk of affective mood switch following ketamine, and both reported a rapid antisuicidal effects. Despite the initial and preliminary findings, further studies are required to examine the clinical efficacy and safety of ketamine in this condition.

\section{Ketamine Administration in PTSD}

One study to date has evaluated the efficacy and safety of ketamine for the treatment of PTSD [57]. This trial compared a single IV dose of ketamine $(0.5 \mathrm{mg} / \mathrm{kg})$ to midazolam $(0.45 \mathrm{mg} / \mathrm{kg})$ in a sample of 35 patients with chronic PTSD. One day after the infusion, patients who received ketamine showed a significant and rapid reduction in PTSD symptom severity, as defined by an improvement on the Impact of Event Scale-Revised (IES-R) score (mean difference in IES-R score, 12.7 [95\%CI, 2.5-22.8]; $P=0.02$ ). The reduction in
PTSD symptoms following treatment with ketamine remained significant after adjusting for depressive symptom severity, suggesting that ketamine may have effects on PTSD-related pathology that is somewhat independent of the comorbidity with depression.

\section{Ketamine Administration in OCD}

A single infusion of a subanesthetic dose of ketamine $(0.5 \mathrm{mg} / \mathrm{kg}$ IV over $40 \mathrm{~min})$ for patients with OCD led to an improvement (defined as a $35 \%$ reduction in the Yale-Brown Obsessive-Compulsive Scale (Y-BOCS)) 1-3 h post-infusion; however, the effects did not persist [71]. Four of the seven subjects with comorbid depression simultaneously experienced acute antidepressant effects (defined by a $50 \%$ improvement in the Hamilton Depression Rating Scale-17 (HDRS-17)). Contrariwise, a more recent, randomized, placebo-controlled trial in 15 medication-free OCD adults, who received two 40-min intravenous infusions (placebo and subanesthetic dose of ketamine at $0.5 \mathrm{mg} / \mathrm{kg}$ ), reported persistent improvement in OCD symptoms (a $35 \%$ reduction in Y-BOCS, 1 week post-infusion) [56] among $50 \%$ of patients. Rodriguez et al. [56] only recruited medication-free subjects, all with near constantly intrusive obsessions and fewer comorbidities. It is possible that this sample was more uniform in its response due to its greater homogeneity, which might explain why this second study exhibited a discrepant outcome relative to the first study in patients with OCD. Considering the paucity of published trials and the differences in results, further studies are required to understand the effect of ketamine on OCD symptoms.

\section{Ketamine and SI}

Although several studies describe an effect of ketamine on suicidality, few trials have been structured in order to investigate specifically the effect of ketamine on suicidality in patients [54, 72, 73]. Price et al. [73] reported a reduction in SI following ketamine infusion based on an analysis in patients with TRD. Ketamine was also reported to have a rapid, beneficial effect on suicidal cognition (defined as greater implicit self-identification with words related to death), with a mean decrease of 2.89 points on the MADRS item pertaining to suicide ( $\max$ score $=6$; no subject was rated $>2$ post-infusion). Diazgranados et al. [54], using the Beck Scale for Suicide Ideation (SSI) in a sample of TRD patients, reported that SI scores decreased significantly $40 \mathrm{~min}$ after ketamine infusion and remained significantly decreased $4 \mathrm{~h}$ post-infusion. In a preliminary open-label prospective study, Larkin and Beautrais [72] explored the feasibility of a single open-label IV dose of ketamine as a $0.2 \mathrm{mg} / \mathrm{kg}$ single bolus over 1-2 min, in 14 MDD patients with SI in an Emergency Department. The authors reported a rapid antidepressant effect within 
240 min with 13 subjects $(92.3 \%)$ meeting response criteria. Moreover, the sample showed a significant decrease on scores of the suicide item on the MADRS $4 \mathrm{~h}$ post-infusion with a sustained reduction at 10-day follow-up.

In summary, the effect of ketamine on SI has been documented after 40 min post-infusion, with variable retention duration from days to weeks [62]. However, further clinical trials specifically addressing SI in larger samples and in controlled condition are required to better understand and to confirm the antisuicidal effects of ketamine.

\section{Limitation of the Current Findings}

Although encouraging, the results emerging from the works published in the past 15 years addressing the potential therapeutic effect of ketamine in mood and anxiety disorders should be considered carefully. Only nine of the published trials on ketamine in mood and anxiety disorders have been evaluated in the context of randomized, placebo-controlled designs and by and large involved small samples enrolled at single centers. The occurrence of dissociative effects associated with ketamine may limit the validity of the blind when an inert placebo comparator is used. The antidepressant effects of a short course of ketamine appear to be transient, perhaps not surprisingly. Data on longer-term therapeutic or adverse effects of longer exposures to ketamine and/or combinations of ketamine with other maintenance or relapse prevention strategies is urgently needed for clinical translation. Additional studies examining alternative routes of administration to IV for repeated ketamine will be important.

\section{Biomarkers of Antidepressant Response to Ketamine}

The identification of biomarkers for ketamine response is very preliminary, although some candidates are beginning to be identified [25]. Predictors of likely antidepressant response to ketamine include increased pretreatment/baseline activity of the anterior cingulate cortex (ACC) during processing of fearful faces, peripheral levels of BDNF, higher baseline vitamin B12 levels, and a low delta sleep ratio (a ratio of delta waves during the first nonrapid eye movement period relative to the second) [74]. BMI, family history of alcohol use disorder, and prior history of suicide attempt have also been shown to correlate with ketamine response [25]. Higher BMI correlated with greater improvement in depression severity (measured with the 17-item Hamilton Depression Rating Scale) at $230 \mathrm{~min}$ and day 1 , while a family history of alcohol use disorder was associated with a greater depressive symptom improvement on days 1 and 7 post-infusion, and a negative history of suicide attempt was associated with greater improvement a week after ketamine infusion. A recent study by Ortiz et al. [75] found that increased baseline expression of Shank3 (a post-synaptic density protein involved in NMDAR tethering and dendritic spine rearrangement, implicated in the pathophysiology of bipolar disorder) predicts acute antidepressant response to ketamine in a sample of 29 subjects with treatment-resistant BD. Moreover, higher baseline levels of Shank3 were also related to larger amygdala volume and increased glucose metabolism in the hippocampus and amygdala [75].

Recently, a sample of 21 treatment-resistant bipolar patients in depressive state underwent [(18)-F]-fluorodeoxyglucose positron emission tomography (PET) scans to assess the metabolic rate of glucose (rMRGlu) after placebo and ketamine infusion in a double-blind randomized crossover study [76]. The authors reported that increased rMRGlu in the ventral striatum was related to antidepressant improvement. Moreover, in a voxel-wise analysis, the sample showed a significantly increased rMRGlu in the subgenual ACC following placebo infusion, which correlated with antidepressant improvement after ketamine infusion. A separate study using functional magnetic resonance imaging (fMRI) in medication-free patients with TRD found reduced neural responses within the right caudate to positively valenced compared to neutral faces [77]. Following ketamine infusion, patients showed an increased response to positive compared to neutral faces in the same neural region (right caudate), appearing to represent a normalization of function following treatment. Greater connectivity of the caudate with multiple cortical and subcortical regions during positive emotion perception was associated with improvement in depression severity. Although preliminary, these findings suggest a specific effect of ketamine on the striatum in relation to neural responses to positive stimuli.

\section{Ketamine Safety and Feasibility}

A recent work by Wan and colleagues [78] analyzed the safety and tolerability from 205 patient infusions of ketamine conducted at a single center. Of these, only four (1.95\%) study participants were discontinued due to adverse events: two for elevated blood pressure during the infusion, one at request of the patient, due to increased anxiety, and one for a transient hypotensive and bradycardic event. Other side effects reached peak levels within 120 min after infusion onset and largely resolved within $24 \mathrm{~h}$. Ketamine infusions have been associated with temporary increases in mean blood pressure and pulse, with minimal change in blood oxygen levels. The most frequently reported side effects have been drowsiness, dizziness, unsteadiness, blurred vision, and feeling strange or unreal. Small increases in psychotic and dissociative symptoms have also been reported but have not remained significantly elevated above baseline after $24 \mathrm{~h}$ of observation. Much more research investigating longer term safety and tolerability of ketamine is required. 
A one long-term assessment (mean length $=2.9 \pm 1.9$ years post-infusion) of ketamine safety showed no persistent physical, emotional, or psychological symptoms after infusions, nor any reports of increased craving or use of ketamine or any other substance of abuse for any of the 46 of 84 $(54.8 \%)$ of patients that responded [78]. A major caveat is that there may have been response bias; those whom the experiments were able to reach may have been those with the least adverse profiles related to ketamine. Considering the use of ketamine as an illicit drug and there are potentially deleterious physical and cognitive consequences of chronic ketamine abuse, more comprehensive, long-term follow-up studies are needed.

\section{Other NMDAR Modulators in Development}

Despite its antidepressant effect, the use of ketamine as a standard treatment for depression on a large scale presents several challenges, including the abuse potential of the drug, an IV route of administration, the potential for transient dissociative or psychotomimetic effects, and an uncertain longerterm safety profile. Given these issues, academic investigators and pharmaceutical companies are actively exploring candidate compounds with activity at the NMDAR or other component of the glutamate system as putative "ketamine-like" drugs. Whether or not a molecule with both a rapid and robust antidepressant effects and an improved tolerability profile compared to ketamine can be developed remains an open question.

A single infusion of AZD6765, a noncompetitive NMDAR, showed a rapid antidepressant effect with minimal psychotomimetic symptoms and tolerable side effects in a sample of 22 patients with TRD [79]. Patients receiving AZD6765 showed a significant improvement in MADRS scores (primary outcome measure) compared to placebo within $80 \mathrm{~min}$ post-infusion, but lasting only through $110 \mathrm{~min}$ post-infusion. A second placebo-controlled trial of repeated dose AZD6765 (three times a week for 3 weeks) enrolled 152 patients with TRD and showed a significant change from baseline at week 3 in MADRS scores compared to placebotreated patients, without psychotomimetic effects [80]. A recently completed 6-week phase IIb study examining the efficacy of adjunctive AZD6765 was reportedly unable to replicate previous findings of clinical efficacy [81, 82]. Currently, the fate of AZD6765 for continued development as an antidepressant is uncertain.

Several other glutamatergic agents with potential antidepressant effects are under investigation. GLYX-13 is a peptide that acts as a partial agonist at the glycine site of the NMDAR and may act as a functional antagonist at higher doses. GLYX13 displays antidepressant action without psychotomimetic effects in animal models of depression [83]. GLYX-13 was associated with an antidepressant response in a rodent model of depression after a single dose, increased synaptic plasticity [83], and a rapid response in the chronic unpredictable stress/ anhedonia model of depression [31]. In a recent trial conducted on a sample of MDD subjects, GLYX-13 reportedly demonstrated a antidepressant effects within $2 \mathrm{~h}$ [84].

The metabolic glutamate receptor (mGluR) represents another important target for the development of antidepressants: the antagonism of these receptors could lead to an increase of extracellular glutamate [30], and evidence from animal studies reports reductions in anhedonic-like behavior [85]. In particular, group II receptors (mGlu2/3) are largely expressed in the CNS, with moderate to high concentration in brain regions commonly associated with MDD (hippocampus, PFC, and amygdala) and are known to alter the neurotransmission of glutamate [16]. The mGlu2/3 antagonist demonstrated antidepressant effects in a rodent model of depression $[85,86]$ and a rapid (within 2 days) and long-lasting (10 days) reversal of anhedonic-like behavior caused by chronic unpredictable stress in rats after a single administration of an $\mathrm{mGlu} 2 / 3$ antagonist [85]. No current studies of mGluR modulators in human depression have been reported, but several clinical trials are currently underway (data from clinicaltrials.gov).

\section{Conclusion}

The discovery of the rapid antidepressant effect of ketamine has triggered a wave of new scientific research and is beginning to shed new light onto the potential role of glutamate in the pathophysiology of depression and the potential for novel glutamate modulators as therapeutics. Despite substantial promise, the published evidence base supporting the efficacy ketamine or other glutamate remains by and large limited to small studies conducted at single centers. Additional studies utilizing randomized designs conducted in larger, representative samples are urgently needed to more fully understand the clinical potential of ketamine as a treatment for severe and refractory forms of mood or anxiety disorders. The risk for transient psychotomimetic and dissociative symptoms likely limits the administration of ketamine to a subpopulation of patients without a history of psychosis. Recent mechanistic studies are beginning to illuminate potential mechanisms of action of ketamine, including effects on AMPA receptors, mTOR signaling, GSK-3 activity, or inflammatory mediators. These mechanisms provide additional opportunities as targets for new drug development.

Acknowledgments Dr. Murrough is supported by a Career Development Award from NIH/NIMH (K23MH094707) and receives additional support from the American Foundation for Suicide Prevention and the Doris Duke Charitable Foundation. The content is solely the responsibility of the authors and does not necessarily represent the official views of the NIH or other funding agency. 


\section{Compliance with Ethics Guidelines}

Conflict of Interest James Murrough has served on advisory boards for Janssen Research and Development and Genentech, has provided consultation services for ProPhase, LLC and Impel Neuropharma, and has received research support from Janssen and Avanir Pharmaceuticals; he is named on a patent pending for the combination of ketamine and lithium to maintain the antidepressant response to ketamine and on a patent pending for the combination of ketamine and lithium for the treatment of suicidal ideation. Dennis Charney and Icahn School of Medicine at Mount Sinai have been named on a use patent on ketamine for the treatment of depression. The Icahn School of Medicine has entered into a licensing agreement for the use of ketamine as therapy for treatmentresistant depression. Charney and Icahn School of Medicine at Mount Sinai could potentially benefit if ketamine were to gain approval for the treatment of depression. Nicholas Van Dam has no personal conflicts to declare. The Icahn School of Medicine, however, is named on a number of patents regarding the use of ketamine for the treatment of depression. Sara Costi has no conflicts relevant to this work.

Human and Animal Rights and Informed Consent This article does not contain any studies with human or animal subjects performed by the author.

\section{References}

1. Ferrari AJ, Charlson FJ, Norman RE, Patten SB, Freedman G, Murray CJ, et al. Burden of depressive disorders by country, sex, age, and year: findings from the global burden of disease study 2010. PLoS Med. 2013;10(11), e1001547.

2. DiLuca M, Olesen J. The cost of brain diseases: a burden or a challenge? Neuron. 2014;82(6):1205-8.

3. Trivedi MH, Rush AJ, Wisniewski SR, Nierenberg AA, Warden D, Ritz L, et al. Evaluation of outcomes with citalopram for depression using measurement-based care in STAR*D: implications for clinical practice. Am J Psychiatry. 2006;163(1):28-40.

4. Gaynes BN, Warden D, Trivedi MH, Wisniewski SR, Fava M, Rush AJ. What did STAR*D teach us? Results from a large-scale, practical, clinical trial for patients with depression. Psychiatr Serv. 2009;60(11):1439-45.

5. Skolnick P, Popik P, Trullas R. Glutamate-based antidepressants: 20 years on. Trends Pharmacol Sci. 2009;30(11):563-9.

6. Berman RM, Cappiello A, Anand A, Oren DA, Heninger GR, Charney DS, et al. Antidepressant effects of ketamine in depressed patients. Biol Psychiatry. 2000;47(4):351-4.

7. Altamura CA, Mauri MC, Ferrara A, Moro AR, D'Andrea G, Zamberlan F. Plasma and platelet excitatory amino acids in psychiatric disorders. Am J Psychiatry. 1993;150(11):1731-3.

8. Mitani H, Shirayama Y, Yamada T, Maeda K, Ashby Jr CR, Kawahara R. Correlation between plasma levels of glutamate, alanine and serine with severity of depression. Prog Neuropsychopharmacol Biol Psychiatry. 2006;30(6):1155-8.

9. Levine J, Panchalingam K, Rapoport A, Gershon S, McClure RJ, Pettegrew JW. Increased cerebrospinal fluid glutamine levels in depressed patients. Biol Psychiatry. 2000;47(7):586-93.

10. Luykx JJ, Laban KG, van den Heuvel MP, Boks MP, Mandl RC, Kahn RS, et al. Region and state specific glutamate downregulation in major depressive disorder: a meta-analysis of (1)H-MRS findings. Neurosci Biobehav Rev. 2012;36(1):198-205.

11. Torrey EF, Webster M, Knable M, Johnston N, Yolken RH. The stanley foundation brain collection and neuropathology consortium. Schizophr Res. 2000;44(2):151-5.
12. Lewis DA. The human brain revisited: opportunities and challenges in postmortem studies of psychiatric disorders. Neuropsychopharmacology. 2002;26(2):143-54.

13. Sanacora G, Gueorguieva R, Epperson CN, Wu YT, Appel M, Rothman DL, et al. Subtype-specific alterations of gammaaminobutyric acid and glutamate in patients with major depression. Arch Gen Psychiatry. 2004;61(7):705-13.

14. Sanacora G. Do glutamatergic agents represent a new class of antidepressant drugs? Part 1. J Clin Psychiatry. 2009;70(10):1473-5.

15. Hashimoto K. Emerging role of glutamate in the pathophysiology of major depressive disorder. Brain Res Rev. 2009;61(2):105-23.

16. Sanacora G, Zarate CA, Krystal JH, Manji HK. Targeting the glutamatergic system to develop novel, improved therapeutics for mood disorders. Nat Rev Drug Discov. 2008;7(5):426-37.

17. Niciu MJ, Kelmendi B, Sanacora G. Overview of glutamatergic neurotransmission in the nervous system. Pharmacol Biochem Behav. 2012;100(4):656-64.

18. Feyissa AM, Chandran A, Stockmeier CA, Karolewicz B. Reduced levels of NR2A and NR2B subunits of NMDA receptor and PSD-95 in the prefrontal cortex in major depression. Prog Neuropsychopharmacol Biol Psychiatry. 2009;33(1):70-5.

19. Preskorn SH, Baker B, Kolluri S, Menniti FS, Krams M, Landen JW. An innovative design to establish proof of concept of the antidepressant effects of the NR2B subunit selective N-methyl-Daspartate antagonist, CP-101,606, in patients with treatmentrefractory major depressive disorder. J Clin Psychopharmacol. 2008;28(6):631-7.

20. Ibrahim L, Diaz Granados N, Jolkovsky L, Brutsche N, Luckenbaugh DA, Herring WJ, et al. A randomized, placebo-controlled, crossover pilot trial of the oral selective NR2B antagonist MK-0657 in patients with treatment-resistant major depressive disorder. J Clin Psychopharmacol. 2012;32(4):551-7.

21. Zhang C, Li Z, Wu Z, Chen J, Wang Z, Peng D, et al. A study of Nmethyl-D-aspartate receptor gene (GRIN2B) variants as predictors of treatment-resistant major depression. Psychopharmacol (Berl). 2014;231(4):685-93.

22. Gray AL, Hyde TM, Deep-Soboslay A, Kleinman JE, Sodhi MS. Sex differences in glutamate receptor gene expression in major depression and suicide. Mol Psychiatry. 2015;20(9):1057-68.

23. Ketamine CR. Anaesthesia. 2007;62 Suppl 1:48-53.

24. Mathew SJ, Shah A, Lapidus K, Clark C, Jarun N, Ostermeyer B, et al. Ketamine for treatment-resistant unipolar depression: current evidence. CNS Drugs. 2012;26(3):189-204.

25. Niciu MJ, Henter ID, Luckenbaugh DA, Zarate Jr CA, Charney DS. Glutamate receptor antagonists as fast-acting therapeutic alternatives for the treatment of depression: ketamine and other compounds. Annu Rev Pharmacol Toxicol. 2014;54:119-39.

26. Yanagihara Y, Ohtani M, Kariya S, Uchino K, Hiraishi T, Ashizawa $\mathrm{N}$, et al. Plasma concentration profiles of ketamine and norketamine after administration of various ketamine preparations to healthy Japanese volunteers. Biopharm Drug Dispos. 2003;24(1):37-43.

27. White PF, Schuttler J, Shafer A, Stanski DR, Horai Y, Trevor AJ. Comparative pharmacology of the ketamine isomers. Studies in volunteers. Br J Anaesth. 1985;57(2):197-203.

28. Abdallah CG, Sanacora G, Duman RS, Krystal JH. Ketamine and rapid-acting antidepressants: a window into a new neurobiology for mood disorder therapeutics. Annu Rev Med. 2015;66:509-23.

29. Zarate Jr CA, Brutsche N, Laje G, Luckenbaugh DA, Venkata SL, Ramamoorthy A, et al. Relationship of ketamine's plasma metabolites with response, diagnosis, and side effects in major depression. Biol Psychiatry. 2012;72(4):331-8.

30. Moghaddam B, Adams B, Verma A, Daly D. Activation of glutamatergic neurotransmission by ketamine: a novel step in the pathway from NMDA receptor blockade to dopaminergic and cognitive 
disruptions associated with the prefrontal cortex. J Neurosci. 1997;17(8):2921-7.

31. Duman RS. Pathophysiology of depression and innovative treatments: remodeling glutamatergic synaptic connections. Dialogues Clin Neurosci. 2014;16(1):11-27.

32. Li N, Liu RJ, Dwyer JM, Banasr M, Lee B, Son H, et al. Glutamate N-methyl-D-aspartate receptor antagonists rapidly reverse behavioral and synaptic deficits caused by chronic stress exposure. Biol Psychiatry. 2011;69(8):754-61.

33. Niciu MJ, Ionescu DF, Richards EM, Zarate Jr CA. Glutamate and its receptors in the pathophysiology and treatment of major depressive disorder. J Neural Transm. 2014;121(8):907-24.

34. Caddy C, Giaroli G, White TP, Shergill SS, Tracy DK. Ketamine as the prototype glutamatergic antidepressant: pharmacodynamic actions, and a systematic review and meta-analysis of efficacy. Ther Adv Psychopharmacol. 2014;4(2):75-99.

35. Autry AE, Adachi M, Nosyreva E, Na ES, Los MF, Cheng PF, et al. NMDA receptor blockade at rest triggers rapid behavioural antidepressant responses. Nature. 2011;475(7354):91-5.

36. Nosyreva E, Szabla K, Autry AE, Ryazanov AG, Monteggia LM, Kavalali ET. Acute suppression of spontaneous neurotransmission drives synaptic potentiation. J Neurosci. 2013;33(16):6990-7002.

37. Li N, Lee B, Liu RJ, Banasr M, Dwyer JM, Iwata M, et al. mTORdependent synapse formation underlies the rapid antidepressant effects of NMDA antagonists. Science. 2010;329(5994):959-64.

38. Beurel E, Song L, Jope RS. Inhibition of glycogen synthase kinase3 is necessary for the rapid antidepressant effect of ketamine in mice. Mol Psychiatry. 2011;16(11):1068-70.

39. Jope RS. Glycogen synthase kinase- 3 in the etiology and treatment of mood disorders. Front Mol Neurosci. 2011;4:16.

40. Beurel E, Grieco SF, Jope RS. Glycogen synthase kinase-3 (GSK3): regulation, actions, and diseases. Pharmacol Ther. 2015;148:114-31.

41. Wu GJ, Chen TL, Ueng YF, Chen RM. Ketamine inhibits tumor necrosis factor-alpha and interleukin- 6 gene expressions in lipopolysaccharide-stimulated macrophages through suppression of toll-like receptor 4-mediated c-Jun N-terminal kinase phosphorylation and activator protein-1 activation. Toxicol Appl Pharmacol. 2008;228(1):105-13.

42. Ward JL, Harting MT, Cox Jr CS, Mercer DW. Effects of ketamine on endotoxin and traumatic brain injury induced cytokine production in the rat. J Trauma. 2011;70(6):1471-9.

43. Miller AH, Maletic V, Raison CL. Inflammation and its discontents: the role of cytokines in the pathophysiology of major depression. Biol Psychiatry. 2009;65(9):732-41.

44. Miller AH. Conceptual confluence: the kynurenine pathway as a common target for ketamine and the convergence of the inflammation and glutamate hypotheses of depression. Neuropsychopharmacology. 2013;38(9):1607-8.

45. Kawasaki T, Ogata M, Kawasaki C, Ogata J, Inoue Y, Shigematsu A. Ketamine suppresses proinflammatory cytokine production in human whole blood in vitro. Anesth Analg. 1999;89(3):665-9.

46. Yang JJ, Wang N, Yang C, Shi JY, Yu HY, Hashimoto K. Serum interleukin-6 is a predictive biomarker for ketamine's antidepressant effect in treatment-resistant patients with major depression. Biol Psychiatry. 2015;77(3):e19-20.

47. Dantzer R, O'Connor JC, Freund GG, Johnson RW, Kelley KW. From inflammation to sickness and depression: when the immune system subjugates the brain. Nat Rev Neurosci. 2008;9(1):46-56.

48. Dowlati Y, Herrmann N, Swardfager W, Liu H, Sham L, Reim EK, et al. A meta-analysis of cytokines in major depression. Biol Psychiatry. 2010;67(5):446-57.

49. Zarate Jr CA, Singh JB, Carlson PJ, Brutsche NE, Ameli R, Luckenbaugh DA, et al. A randomized trial of an N-methyl-Daspartate antagonist in treatment-resistant major depression. Arch Gen Psychiatry. 2006;63(8):856-64.
50. Lapidus KA, Levitch CF, Perez AM, Brallier JW, Parides MK, Soleimani $\mathrm{L}$, et al. A randomized controlled trial of intranasal ketamine in major depressive disorder. Biol Psychiatry. 2014;76(12): $970-6$.

51. Murrough JW, Iosifescu DV, Chang LC, Al Jurdi RK, Green CE, Perez AM, et al. Antidepressant efficacy of ketamine in treatmentresistant major depression: a two-site randomized controlled trial. Am J Psychiatry. 2013;170(10):1134-42.

52. Murrough JW, Perez AM, Pillemer S, Stern J, Parides MK, Aan het Rot M, et al. Rapid and longer-term antidepressant effects of repeated ketamine infusions in treatment-resistant major depression. Biol Psychiatry. 2013;74(4):250-6.

53. Valentine GW, Mason GF, Gomez R, Fasula M, Watzl J, Pittman B, et al. The antidepressant effect of ketamine is not associated with changes in occipital amino acid neurotransmitter content as measured by [(1)H]-MRS. Psychiatry Res. 2011;191(2):122-7.

54. DiazGranados N, Ibrahim LA, Brutsche NE, Ameli R, Henter ID, Luckenbaugh DA, et al. Rapid resolution of suicidal ideation after a single infusion of an N-methyl-D-aspartate antagonist in patients with treatment-resistant major depressive disorder. J Clin Psychiatry. 2010;71(12):1605-11.

55. Zarate Jr CA, Brutsche NE, Ibrahim L, Franco-Chaves J, Diazgranados N, Cravchik A, et al. Replication of ketamine's antidepressant efficacy in bipolar depression: a randomized controlled add-on trial. Biol Psychiatry. 2012;71(11):939-46.

56. Rodriguez CI, Kegeles LS, Levinson A, Feng T, Marcus SM, Vermes D, et al. Randomized controlled crossover trial of ketamine in obsessive-compulsive disorder: proof-of-concept. Neuropsychopharmacology. 2013;38(12):2475-83.

57. Feder A, Parides MK, Murrough JW, Perez AM, Morgan JE, Saxena S, et al. Efficacy of intravenous ketamine for treatment of chronic posttraumatic stress disorder: a randomized clinical trial. JAMA Psychiatry. 2014;71(6):681-8.

58. Carlson PJ, Diazgranados N, Nugent AC, Ibrahim L, Luckenbaugh DA, Brutsche N, et al. Neural correlates of rapid antidepressant response to ketamine in treatment-resistant unipolar depression: a preliminary positron emission tomography study. Biol Psychiatry. 2013;73(12):1213-21.

59. Rasmussen KG, Lineberry TW, Galardy CW, Kung S, Lapid MI, Palmer BA, et al. Serial infusions of low-dose ketamine for major depression. J Psychopharmacol. 2013;27(5):444-50.

60. Ibrahim L, Diazgranados N, Franco-Chaves J, Brutsche N, Henter ID, Kronstein P, et al. Course of improvement in depressive symptoms to a single intravenous infusion of ketamine vs add-on riluzole: results from a 4-week, double-blind, placebo-controlled study. Neuropsychopharmacology. 2012;37(6):1526-33.

61. Mathew SJ, Murrough JW, Aan het Rot M, Collins KA, Reich DL, Charney DS. Riluzole for relapse prevention following intravenous ketamine in treatment-resistant depression: a pilot randomized, placebo-controlled continuation trial. Int J Neuropsychopharmacol. 2010;13(1):71-82.

62. Aan het Rot M, Collins KA, Murrough JW, Perez AM, Reich DL, Charney DS, et al. Safety and efficacy of repeated-dose intravenous ketamine for treatment-resistant depression. Biol Psychiatry. 2010;67(2):139-45.

63. Liebrenz M, Stohler R, Borgeat A. Repeated intravenous ketamine therapy in a patient with treatment-resistant major depression. World J Biol Psychiatry. 2009;10(4 Pt 2):640-3.

64. Segmiller F, Ruther T, Linhardt A, Padberg F, Berger M, Pogarell $\mathrm{O}$, et al. Repeated S-ketamine infusions in therapy resistant depression: a case series. J Clin Pharmacol. 2013;53(9):996-8.

65. Shiroma PR, Johns B, Kuskowski M, Wels J, Thuras P, Albott CS, et al. Augmentation of response and remission to serial intravenous subanesthetic ketamine in treatment resistant depression. J Affect Disord. 2014; 155:123-9. 
66. Kranaster L, Kammerer-Ciernioch J, Hoyer C, Sartorius A. Clinically favourable effects of ketamine as an anaesthetic for electroconvulsive therapy: a retrospective study. Eur Arch Psychiatry Clin Neurosci. 2011;261(8):575-82.

67. Okamoto N, Nakai T, Sakamoto K, Nagafusa Y, Higuchi T, Nishikawa T. Rapid antidepressant effect of ketamine anesthesia during electroconvulsive therapy of treatment-resistant depression: comparing ketamine and propofol anesthesia. J ECT. 2010;26(3): 223-7.

68. Wang X, Chen Y, Zhou X, Liu F, Zhang T, Zhang C. Effects of propofol and ketamine as combined anesthesia for electroconvulsive therapy in patients with depressive disorder. J ECT. 2012;28(2):128-32.

69. Loo CK, Katalinic N, Garfield JB, Sainsbury K, Hadzi-Pavlovic D, Mac-Pherson R. Neuropsychological and mood effects of ketamine in electroconvulsive therapy: a randomised controlled trial. J Affect Disord. 2012;142(1-3):233-40.

70. Abdallah CG, Fasula M, Kelmendi B, Sanacora G, Ostroff R. Rapid antidepressant effect of ketamine in the electroconvulsive therapy setting. J ECT. 2012;28(3):157-61.

71. Bloch MH, Wasylink S, Landeros-Weisenberger A, Panza KE, Billingslea E, Leckman JF, et al. Effects of ketamine in treatmentrefractory obsessive-compulsive disorder. Biol Psychiatry. 2012;72(11):964-70.

72. Larkin GL, Beautrais AL. A preliminary naturalistic study of lowdose ketamine for depression and suicide ideation in the emergency department. Int J Neuropsychopharmacol. 2011;14(8):1127-31.

73. Price RB, Iosifescu DV, Murrough JW, Chang LC, Al Jurdi RK, Iqbal SZ, et al. Effects of ketamine on explicit and implicit suicidal cognition: a randomized controlled trial in treatment-resistant depression. Depress Anxiety. 2014;31(4):335-43.

74. Duncan Jr WC, Selter J, Brutsche N, Sarasso S, Zarate Jr CA. Baseline delta sleep ratio predicts acute ketamine mood response in major depressive disorder. J Affect Disord. 2013;145(1):115-9.

75. Ortiz R, Niciu MJ, Lukkahati N, Saligan LN, Nugent AC, Luckenbaugh DA, et al. Shank3 as a potential biomarker of antidepressant response to ketamine and its neural correlates in bipolar depression. J Affect Disord. 2014;172C:307-11.

76. Nugent AC, Diazgranados N, Carlson PJ, Ibrahim L, Luckenbaugh DA, Brutsche N, et al. Neural correlates of rapid antidepressant response to ketamine in bipolar disorder. Bipolar Disord. 2014;16(2):119-28.
77. Murrough JW, Collins KA, Fields J, DeWilde KE, Phillips ML, Mathew SJ, et al. Regulation of neural responses to emotion perception by ketamine in individuals with treatment-resistant major depressive disorder. Transl Psychiatry. 2015;5, e509.

78. Wan LB, Levitch CF, Perez AM, Brallier JW, Iosifescu DV, Chang LC, et al. Ketamine safety and tolerability in clinical trials for treatment-resistant depression. J Clin Psychiatry. 2015;76(3):24752.

79. Zarate Jr CA, Mathews D, Ibrahim L, Chaves JF, Marquardt C, Ukoh I, et al. A randomized trial of a low-trapping nonselective N-methyl-D-aspartate channel blocker in major depression. Biol Psychiatry. 2013;74(4):257-64.

80. Sanacora G, Smith MA, Pathak S, Su HL, Boeijinga PH, McCarthy DJ, et al. Lanicemine: a low-trapping NMDA channel blocker produces sustained antidepressant efficacy with minimal psychotomimetic adverse effects. Mol Psychiatry. 2014;19(9):978-85.

81. Sanacora G, Schatzberg AF. Ketamine: promising path or false prophecy in the development of novel therapeutics for mood disorders? Neuropsychopharmacology. 2015;40(2):259-67.

82. Iadarola ND, Niciu MJ, Richards EM, Vande Voort JL, Ballard ED, Lundin NB, et al. Ketamine and other N-methyl-D-aspartate receptor antagonists in the treatment of depression: a perspective review. Ther Adv Chronic Dis. 2015;6(3):97-114.

83. Burgdorf J, Zhang XL, Nicholson KL, Balster RL, Leander JD, Stanton PK, et al. GLYX-13, a NMDA receptor glycine-site functional partial agonist, induces antidepressant-like effects without ketamine-like side effects. Neuropsychopharmacology. 2013;38(5):729-42.

84. Preskorn S, Macaluso M, Mehra DO, Zammit G, Moskal JR, Burch RM, et al. Randomized proof of concept trial of GLYX-13, an Nmethyl-D-aspartate receptor glycine site partial agonist, in major depressive disorder nonresponsive to a previous antidepressant agent. J Psychiatr Pract. 2015;21(2):140-9.

85. Dwyer JM, Lepack AE, Duman RS. mGluR2/3 blockade produces rapid and long-lasting reversal of anhedonia caused by chronic stress exposure. J Mol Psychiatry. 2013;17(1):15,9256-1-15. eCollection.

86. Chaki S, Yoshikawa R, Hirota S, Shimazaki T, Maeda M, Kawashima N, et al. MGS0039: a potent and selective group II metabotropic glutamate receptor antagonist with antidepressantlike activity. Neuropharmacology. 2004;46(4):457-67. 